\title{
Flattening the COVID-19 Curve: The Impact of Contact Restrictions on the Infection Curve in Germany
}

\author{
Die Abflachung der COVID-19 Kurve: Der Einfluss von \\ Kontaktbeschränkungen auf die Infektionskurve in Deutschland
}

\section{Autoren \\ Johann Valentowitsch}

\author{
Affiliation \\ Betriebswirtschaftliches Institut, Universität Stuttgart, \\ Stuttgart
}

Key words

COVID-19, Coronavirus, Contact Restrictions

\section{Schlüsselwörter}

COVID-19, Coronavirus, Kontaktbeschränkungen

\author{
Bibliografie \\ DOI https://doi.org/10.1055/a-1194-4967 \\ Gesundheitswesen 2020; 82: 646-648 \\ (c) Georg Thieme Verlag KG Stuttgart · New York \\ ISSN 0941-3790
}

\section{Correspondence}

Dr. Johann Valentowitsch

Betriebswirtschaftliches Institut

Universität Stuttgart

KeplerStraße 17

70174 Stuttgart

johann.valentowitsch@bwi.uni-stuttgart.de

\begin{abstract}
Although Germany is coping well with the coronavirus crisis, many voices are currently being raised that fundamentally question the success of the contact restriction strategy to contain the virus. I show in this study that there is no justification for such criticism. In fact, contact restrictions have flattened the infection curve and were possibly decisive for the good German performance in the crisis.
\end{abstract}

\section{ZUSAMMENFASSUNG}

Obwohl Deutschland mit der Coronavirus-Krise gut zurechtkommt, werden derzeit viele Stimmen laut, die den Erfolg der Kontaktbeschränkungsstrategie zur Eindämmung des Virus grundlegend in Frage stellen. Ich zeige in dieser Studie, dass es keine Rechtfertigung für eine solche Kritik gibt. Die Einschränkung sozialer Kontakte hat tatsächlich einen wesentlichen Beitrag zur Abflachung der Infektionskurve geleistet und war damit maßgebend für das gute deutsche Krisenmanagement.

\section{Introduction}

In many parts of the world, Germany is seen as a model and exemplary country in the fight against the new cornavirus. Compared to the rest of the world, Germany has one of the lowest case fatality rates and handles the coronavirus crisis very well [2]. Germany also seems to have got the infection rate under control relatively quickly. According to estimates by the Robert Koch Institute, the effective basic reproductive number dropped below the critical mark just a few weeks after the outbreak of the disease [6]. In addition to the good German health care system, the massive political crackdown of social life is held responsible for the rapid success in disease control. In order to stop the spread of the coronavirus, German politics has largely shut down large parts of public and cultural life. Schools and daycare centers were closed, companies were asked to send their employees home, and extensive contact restrictions were put in place - in short: public life was torn out of normality and, wherever possible, put into an artificial deep sleep.
However, from an economic point of view, the consequences of the social lockdown are gigantic and cannot be compared to any other crisis in the post-war period. Economists recently predicted a drop in German gross domestic product up to $10 \%$ this year [3]. In the end, the social lockdown will most likely rob many people of their economic existence and drive many companies into bankruptcy. Against this background, voices were rasied early, just like in other countries that pursue a strategy similar to Germany, which called for a rapid end to the drastic measures or even questioned the usefulness of the contact restriction strategy as a whole. Thus, given the current situation, it is important to know how effectively the lockdown actually helps to contain the epidemic.

Based on this question, I will show that the contact restriction strategy has fundamentally not missed its target. Even if many people question the success of the strategy, social distancing has actually led to a massive reduction in the infection rate and thus made 
it possible to flatten the infection curve. According to the results of my estimate, the infection rate in Germany would be many times higher without contact restrictions. The temporary lockdown of social life was therefore an important and correct step to contain the disease.

\section{Methods}

In this study, I look at the daily infection rate in Germany and, based on a set of plausible basic reproduction numbers, estimate how the infection rate would have developed had the social lockdown not occurred. I therefore estimate a counterfactual scenario based on the actual infection dynamics that could be observed in the first weeks before the first political interventions.

For the calibration of the estimate I use the number of cases documented by the Robert Koch Institute, an independent German fe- deral authority for infectious diseases and non-communicable diseases. In my study, the calibration sample began at the end of February with the appearance of the first local outbreaks, which, unlike in January, could no longer be completely controlled by the authorities through quarantine measures. The end of the calibration sample marks March $30^{\text {th }}$.

The first political decisions that worked towards a comprehensive restriction of social contacts in Germany can be dated back to March 16 [3]. For my investigation, I assumed that the effects of the corona regulations on the case number statistics will manifest themselves about 2 weeks later. I am guided by the official assessment of the Robert Koch Institute, according to which the case statistics in Germany document the situation around 2 weeks later [6]. The Robert Koch Institute gives 2 main reasons for the delay in statistics. On the one hand, in most cases it takes about 5-7 days between being infected and going to the doctor, and on the other

\section{Actual and estimated course of infection after the German lockdown}

Simulation for $\mathbf{R}=\mathbf{2 . 0}, \mathbf{R}=\mathbf{2 . 2 5}$ and $\mathrm{R}=\mathbf{2 . 5}$

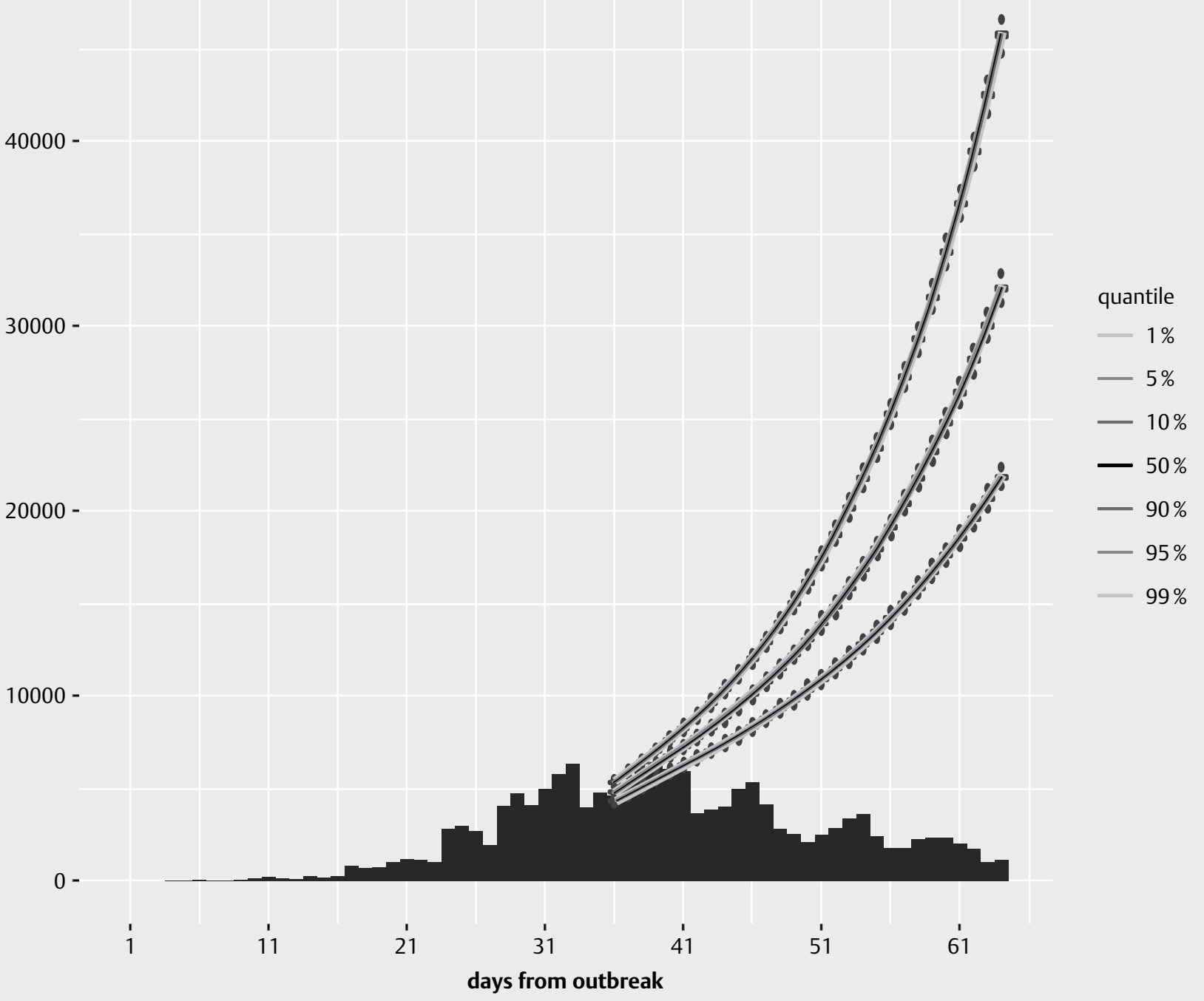

Fig. 1 
hand, another 7 days pass from the laboratory detection of the infection to the notification of the illness to the Robert Koch Institute. In Germany, the federal organization of health authorities can be held responsible for the comparatively long transmission of infection numbers. The German health authorities first aggregate the data at the level of individual regional districts and only then report the case numbers to the Robert Koch Institute in Berlin [6].

For the counterfactual simulation of the disease development from March $30^{\text {th }}$, I used a branching process model based on the renewal equation [1]. The methodological approach used in this study builds on Nouvellet et al. [4]. The model simulation is based on the estimation of the serial interval, which represents the duration between symptom onset of a secondary case and that of its primary case, and the estimation of the basic reproduction number, which describes the expected number of cases directly generated by one case in a population where all individuals are susceptible to infection. The serial interval was assumed to be gamma distributed with parameters taken from the literature. Initial studies indicate a serial interval between 4 and 8 days for the novel coronavirus [5]. The basic reproduction number for the simulation estimates was also borrowed from the literature. The World Health Organization estimates that the basic reproductive count for the new type of coronavirus would be between 2 and 2.5 without state intervention [7]. Based on this, each infected person would have to infect about 2 more people with the virus on average, which would lead to an exponential increase in the number of cases.

\section{Results and Discussion}

Simulation results are summarized in $\triangleright \mathbf{F i g}$. 1 . As can be seen from the illustration, the social lockdown broke the infection line and greatly weakened the exponential increase in the number of infections. Without political intervention, the number of infections should have been 20 to 50 times higher than at the current level.

These days, not only in Germany, there is much controversy about the usefulness of government interventions in social life. The debate is often emotional and is much more based on guesswork than fact. I have shown that there is currently no reason to doubt the effectiveness of the social lockdown measures. Based on the results of my analysis, it is obvious that contact restrictions are contributing to the slowing down of the virus epidemic. Nevertheless, the question must be asked how long such measures can be maintained without the economy collapsing or acceptance of the population disappearing. Moreover, the social lockdown effect may not prove to be sustainable because people do not want to stick to the strict rules for long and neglect the risk of infection over time. However, since the disease is not yet completely contained, such negligence can overturn the positive development of infection dynamics at any time and quickly bring the development of case numbers back to the point of exponential increase.

Germany is currently well positioned in the coronavirus crisis, which can be attributed not least to the effect of the official contact restriction measures. Other countries that decided social distancing too late or simply did not consider it as a real option for action are now much worse off and have significantly increased mortality rates. While the utilization of intensive care beds did not yet reach its capacity limit in German hospitals even at the height of the crisis, triage decisions had to be made elsewhere and patients had to be ventilated selectively [2]. The German special route, of which the rest of the world often speaks with admiration, is actually not very puzzling in itself. Rather, the current situation in Germany testifies to the effectiveness of the measures taken at an early stage, the success of which, however, is fragile and prone to setbacks.

\section{Conflict of Interest}

The authors declare that they have no conflict of interest.

\section{References}

[1] Fraser C. Estimating individual and household reproduction numbers in an emerging epidemic. PLoS One 2007; 2: e758

[2] Ghiasvand S. Predicting the prevalence of COVID-19 pandemic in Germany. Working Paper 2020; Technical University of Dresden.

[3] Hüther M, Bardt $\mathrm{H}$. An economic policy exit strategy from the corona lockdown. Wirtschaftsdienst 2020; 100: 277-284

[4] Nouvellet P, Cori A, Garske T et al. A simple approach to measure transmissibility and forecast incidence. Epidemics 2018; 22: 29-35

[5] Park M, Cook AR, Lim JT et al. A Systematic Review of COVID-19 Epidemiology Based on Current Evidence. Journal of Clinical Medicine 2020; 9: 967

[6] RKI. Täglicher Lagebericht des RKI zur Coronavirus-Krankheit-2019 (COVID-19). Robert Koch Institute; 2020

[7] WHO. Report of the WHO-China Joint Mission on Coronavirus Disease 2019 (COVID-19). Report. World Health Organization (WHO); 2020 